\title{
Postural stability of workers exposed to lead
}

\author{
S E Chia, L H Chua, T P Ng, S C Foo, J Jeyaratnam
}

\begin{abstract}
Objective-To detect, with a computerised postural sway measurement system, any significant deviation of postural sway parameters among lead workers compared with a control group.

Methods-Postural stability was investigated with a computerised postural sway measurement system in 60 workers exposed to lead with a duration of exposure of 84 (range 3-366) months and 60 controls. Sway parameter data were collected with an Advanced Mechanical Technology computerised biomechanics platform system.
\end{abstract}

Results-The mean current blood lead concentration was 36.0 (range 6.4 to 64.5 ) $\mu \mathrm{g} / \mathrm{dl}$ for the exposed workers and 6.3 (range 3.1 to 10.9 ) $\mu \mathrm{g} / \mathrm{dl}$ for the $14 \mathrm{con}$ trols. There was no significant difference between the groups for the postural sway parameters obtained when the eyes were open. Significant differences were found for $X_{s}, Y_{s}$ (SDs of the coordinates of the centre of pressure); $X_{m}, Y_{m}$ (mean deviation of the coordinates of the centre of pressure); $\mathbf{R}_{\mathbf{m}}$ (average displacement of $X_{i}, Y_{i}$, from $X_{o}, Y_{o}$ ); $L$ (length of sway path); Vel (mean velocity of the centre of pressure along its path); $\mathbf{A}_{0}$ (area included within the path of the centre of pressure); $A_{e}(95 \%$ confidence elliptical area). The Romberg ratios (the relation between eyes closed and open) for the Vel, $L, A_{0}$ and $A_{e}$ of the exposed workers were also significantly different from the controls.

Conclusion-The study showed that workers exposed to lead had significantly poorer postural stability than the controls. Lead may affect certain parts of the whole sensory neural axis resulting in postural instability when the visual input is cut off. Based on current blood lead concentrations, we were not able to obtain any significant association with the postural sway parameters.

\section{(Occup Environ Med 1994;51:768-771)}

Keywords: computerised postural sway, lead, blood

The maintenance of standing posture has long been associated with assessments of function of the nervous system. ${ }^{1}$ Terms to denote this include postural sway, postural stability, human equilibrium, postural equilibrium, standing steadiness, and body sway. Computerised postural sway measurements have been used primarily in the field of physiology and pharmacology, ${ }^{2-4}$ mostly in controlled experimental settings ${ }^{56}$ to study the effect of drugs on postural stability.

Few researchers, however, have attempted to use computerised postural sway equipment to study the postural function of workers exposed to neurotoxic substances. ${ }^{7-10}$ Abnormalities of postural sway have been associated with lead intoxication predominantly in children. ${ }^{11} 12$ There was a case report of possible effects of lead on postural stability in an adult. Linz et al reported improvement in postural sway test performance after $\mathrm{Ca}^{++}$EDTA chelation in an adult worker with persistent symptoms of the central nervous system two years after an episode of subacute lead intoxication. ${ }^{13}$ To our knowledge, there are no reports of the effects of lead on postural balance among workers exposed to lead.

The objectives of this study were to detect, with a computerised postural sway measurement system, any significant deviation from normal of postural sway parameters among a group of workers who were exposed to lead.

\section{Methods}

STUDY POPULATION

The study was carried out at a factory that manufactures lead storage batteries. Of a total of 63 male workers who are directly exposed to lead, 60 agreed to participate in the study. Sixty subjects who were clinically healthy and had no exposure to neurotoxic agents served as controls.

No important differences were noted in the age, height, weight, and drink habits between the exposed and control groups (table 1). None of the exposed or control subjects consumed more than $50 \mathrm{~g}$ of alcohol a day. Most were social drinkers, that is, drinking alcohol less than once a month. For the exposed group, the mean duration of lead exposure was 84 (range 3-366) months. Twenty six $(43.3 \%)$ workers had more than five years of exposure.

Table 1 Characteristics of study population

\begin{tabular}{lcc}
\hline & $\begin{array}{l}\text { Exposed } \\
\text { mean }(S D) \\
(n=60)\end{array}$ & $\begin{array}{l}\text { Control } \\
\text { mean }(S D) \\
(n=60)\end{array}$ \\
\hline Age $(\mathrm{y})$ & $31 \cdot 6(7 \cdot 7)$ & $35 \cdot 4(7 \cdot 4)$ \\
Height $(\mathrm{cm})$ & $166 \cdot 3(8 \cdot 1)$ & $169 \cdot 3(6 \cdot 2)$ \\
Weight $(\mathrm{kg})$ & $65 \cdot 2(11 \cdot 7)$ & $64 \cdot 9(7 \cdot 6)$ \\
Subjects who drank $(\%)^{\star}$ & $5 \cdot 0$ & $11 \cdot 7$ \\
Exposure (months) & $84 \cdot 0(86 \cdot 7)$ & - \\
Blood lead ( $\mu \mathrm{g} / \mathrm{dl})$ & $36 \cdot 0(11 \cdot 7)$ & $6 \cdot 3(2 \cdot 4) \dagger$
\end{tabular}

*All of the subjects who drank were occasional and social drinkers, they drank less than once a month, each time no more than two large bottles of beer.

tResults for 14 controls. 
All the exposed subjects and a sample of the controls $(n=14)$ had venous blood collected, on the day the postural sway tests were conducted, for determination of whole blood lead concentrations. We did not see the need to subject all the controls to a blood test when the records did not suggest any lead exposure. Thus we randomly took blood samples from 14 controls to confirm this.

The blood specimens for lead analysis were collected in lead free heparinised polypropylene containers. Precautions were taken to prevent contamination as far as possible. Blood lead concentrations were determined by an electrothermal atomic absorption spectrophotometer with an autosampler. ${ }^{14}$ The analyses were carried out in triplicate. The SD for within run precision (based on 15 repetitive measurements) for a blood lead concentration of $8 \mu \mathrm{g} / \mathrm{dl}$ was 0.34 and for a blood lead concentration of $80 \mu \mathrm{g} / \mathrm{dl}$ was 0.67 . The coefficient of variation seldom exceeded $6 \%$. The precision of blood lead analysis in this laboratory over the range of 4 to $80 \mu \mathrm{g} / \mathrm{dl}$ was $0 \cdot 12 \mu \mathrm{g} / \mathrm{dl}$. External quality control was carried out in collaboration with the National External Quality Control Assessment Scheme in the United Kingdom. The mean running variance index score at the time of analysis was 24-28.

\section{STUDY DESIGN \\ Questionnaire}

Information was gathered on age, years of education, medical and drug history, detailed occupational history, and present and past smoking habits. Alcohol intake was also documented carefully as it could confound the findings. Actual amount of alcohol consumption a day and number of years of drinking were noted. All the interviews were conducted blind by only one trained field investigator throughout the study.

Age was recorded as at the last birthday. Standing height was measured in centimetres with the subject barefoot. Weight (in light street clothes without shoes) was recorded to the nearest tenth of a kilogram with the same weighing scale, which was calibrated each time before weighing.

\section{Clinical examination}

Each subject was examined clinically by one of the authors (SEC) throughout the study. The examination included assessment of past pointing, diadochokinesis, evaluation of walking gait, turning, reflexes, and the musculoskeletal system. No abnormalities were detected clinically for either exposed or control groups.

\section{Computerised assessment of postural sway}

Each subject was given two sets of tests. The first set consisted of three tests (each lasting $20 \mathrm{~s}$ ) conducted with the eyes open. The second set consisted of three tests (also $20 \mathrm{~s}$ each) that were conducted with the eyes closed. The subject was asked to focus on a fixed picture placed at eye level throughout the measurement. For the tests with eyes closed, the subject was asked to close his eyes for a $10 \mathrm{~s}$ interval before the start of recording. Subjects stood in their bare feet on the platform, arms at their side, feet separated. This was assured by footprints marked on the platform surface. All the subjects had the tests between 900 and $1130 \mathrm{am}$. This was to reduce possible effects of circidian rhythms. All the measurements were conducted blind by only one technician throughout the study.

The technician monitored the postural sway of the subjects on the computer screen as the tests were conducted. A particular test was repeated when any extraneous body movements were identified during the measurement. Before the test, care was taken to ensure that the platform was resting level on the floor. The equipment was housed in the office buildings. There were no movements of heavy vehicles in the vicinity. Vibration effects on the platform, if any, would have been minimal.

Equipment-Sway parameter data were collected with an Advanced Mechanical Technology computerised biomechanics platform system. The system consists of six components, high frequency response $(1000 \mathrm{~Hz})$, OR6-6 force platform with temperature compensation, foil type stain gauge transducers, a GSA6 signal conditioner and amplifier, and an ICL notebook. The force platform was placed on the floor of the factory office away from the production area.

Sway parameters-Software supplied by Advanced Mechanical Technology (BEDAS2 computer automated stability analysis) was used to compute the parameters of changes in the centre of pressure from data taken while the subject was standing on the platform. The location of the centre of pressure was calculated by the equations:

$\mathrm{X}=\frac{(\mathrm{My}-\mathrm{Z} \times \mathrm{Fz})}{\mathrm{Fz}}$ and $\mathrm{Y}=\frac{(\mathrm{Mx}+\mathrm{Z} \times \mathrm{Fy})}{\mathrm{Fz}}$

where $\mathrm{My}$ is the moment about the $\mathrm{Y}$ axis, $\mathrm{Mx}$ is the moment about the $\mathrm{X}$ axis, $\mathrm{Fz}$ is the vertical force, and $Z$ is the distance from the top surface of the platform to its dynamic centre. In laboratory simulated tests involving different weights the force platform accuracy in detecting the location of the centre of pressure was within $0.05 \mathrm{~cm}$.

The sway parameters used for detecting changes in performance were: $\mathrm{X}_{\mathrm{o}}, \mathrm{Y}_{\mathrm{O}}$ (mean centre pressure relative to the centre of the platform); $\mathrm{X}_{\mathrm{s}}, \mathrm{Y}_{\mathrm{s}}$ (SDs of the coordinates of the centre of pressure); $X_{m}, Y_{m}$ (mean deviation of the coordinates of the centre of pressure); $R_{m}$ (average displacement of $X_{i}, Y_{i}$, from $\mathrm{X}_{\mathrm{o}}, \mathrm{Y}_{\mathrm{o}}$ ); $\mathrm{L}$ (length of sway path); Vel (mean velocity of the centre of pressure along its path); $A_{0}$ (area included within the path of the centre of pressure); and $A_{e}$ (95\% confidence elliptical area).

Reproducibility of sway parameters-During the study, the postural sway of seven separate subjects was tested by the same procedure. Each of the subjects repeated the postural sway tests on six consecutive days. Analysis of the results of the seven subjects collected over 
Table 2 Correlation coefficient (r) for height, weight, age, and eyes open or closed with postural sway (exposed and control subjects)

\begin{tabular}{|c|c|c|c|c|c|c|}
\hline & \multicolumn{3}{|l|}{ Eyes open } & \multicolumn{3}{|l|}{ Eyes closed } \\
\hline & Age (y) & Height $(\mathrm{cm})$ & Weight (kg) & Age (y) & Height $(\mathrm{cm})$ & Weight $(\mathrm{kg})$ \\
\hline $\begin{array}{l}\mathbf{X}_{\mathrm{o}}(\mathrm{cm}) \\
\mathbf{Y}_{0}(\mathrm{~cm}) \\
\mathbf{X}_{\mathrm{s}}(\mathrm{cm}) \\
\mathbf{Y}_{\mathrm{s}}(\mathrm{cm}) \\
\mathbf{X}_{\mathrm{m}}(\mathrm{cm}) \\
\mathbf{Y}_{\mathrm{m}}(\mathrm{cm}) \\
\mathbf{R}_{\mathrm{m}}(\mathrm{cm}) \\
\text { Vel }(\mathrm{cm} / \mathrm{s}) \\
\mathbf{L}(\mathrm{cm}) \\
\mathbf{A}_{0}\left(\mathrm{~cm}^{2}\right) \\
\mathbf{A}_{e}\left(\mathrm{~cm}^{2}\right)\end{array}$ & $\begin{array}{r}0.003 \\
-0.002 \\
0.125 \\
-0.041 \\
0.106 \\
-0.054 \\
0.049 \\
0.131 \\
0.131 \\
0.038 \\
0.023\end{array}$ & $\begin{array}{l}0 \cdot 095 \\
0 \cdot 141 \\
0 \cdot 094 \\
0 \cdot 269^{\star \star} \\
0 \cdot 102 \\
0 \cdot 255^{\star \star} \\
0 \cdot 178 \\
0 \cdot 181^{\star} \\
0 \cdot 181^{\star} \\
0 \cdot 210^{\star} \\
0 \cdot 237^{\star \star}\end{array}$ & $\begin{array}{l}0 \cdot 045 \\
0 \cdot 090 \\
0 \cdot 222^{\star} \\
0 \cdot 243^{\star \star} \\
0 \cdot 216^{\star} \\
0 \cdot 219^{\star} \\
0 \cdot 245^{\star \star} \\
0 \cdot 270^{\star \star} \\
0 \cdot 270^{\star \star} \\
0 \cdot 306^{\star \star \star} \\
0 \cdot 288^{\star \star}\end{array}$ & $\begin{array}{l}-0.020 \\
-0.066 \\
-0.015 \\
-0.188^{\star} \\
-0.026 \\
-0.178 \\
-0.095 \\
0.018 \\
0.018 \\
-0.075 \\
-0.091\end{array}$ & $\begin{array}{l}0 \cdot 136 \\
0 \cdot 163 \\
0 \cdot 285^{\star \star} \\
0 \cdot 405^{\star \star \star} \\
0 \cdot 276^{\star \star} \\
0.384^{\star \star \star} \\
0 \cdot 341^{\star \star \star} \\
0 \cdot 278^{\star \star} \\
0 \cdot 280^{\star \star} \\
0 \cdot 369^{\star \star \star} \\
0 \cdot 386^{\star \star \star}\end{array}$ & $\begin{array}{c}-0.035 \\
0.120 \\
0 \cdot 414^{\star \star \star} \\
0.438^{\star \star \star} \\
0.418^{\star \star \star} \\
0.437^{\star \star \star} \\
0.466^{\star \star \star} \\
0.343^{\star \star \star} \\
0.343^{\star \star \star} \\
0.461^{\star \star \star} \\
0.470^{\star \star \star}\end{array}$ \\
\hline
\end{tabular}

${ }^{\star \star \star} \mathrm{P}<0.001 ;{ }^{\star \star} \mathrm{P}<0.01 ;{ }^{\star} \mathrm{P}<0.05$.

$X_{0}, Y_{0}=$ average position of centre of pressure on platform; $X_{s}, Y_{s}=$ SDs of the coordinates of the centre of pressure; $X_{m}, Y_{m}=$ average deviation of the coordinates of the centre of pressure; $R_{m}=$ average displacement of $X_{i}, Y_{i}$, from $X_{0}, Y_{o} ; V e l=a v e r a g e$ speed of centre of pressure along its path; $L=$ length of sway path; $A_{0}=$ area included within the path of the centre of pressure; $\mathrm{A}_{\mathrm{e}}=95 \%$ confidence elliptical area.

six days did not show any significant within subject variation.

\section{STATISTICS}

Logarithmic transformation was applied to all the sway parameter data to improve its normality. Differences between the exposed and control postural sway parameters were tested by analysis of variance with adjustment for height, weight, age, and drink habits. The statistical analysis was run on an IBM 3081 mainframe computer with the Statistical Analysis System package. The PROC CORR, and PROC GLM procedures were used.

\section{Results}

Height and weight were significantly correlated with most of the postural sway parameters both for open and closed eyes. Age was not significantly correlated with the postural sway parameters (table 2 ). There were significant differences between the exposed and control groups for $X_{s}, Y_{s}, X_{m}, Y_{m}, R_{m}$, Vel, $L$, $A_{0}$, and $A_{e}$ when the eyes were closed. No significant differences were noted between the exposed and control groups for the sway para-

Table 3 Postural sway parameters for exposed and control groups

\begin{tabular}{|c|c|c|c|c|}
\hline Eyes & $\begin{array}{l}\text { Postural } \\
\text { sway } \\
\text { parameters }\end{array}$ & $\begin{array}{l}\text { Exposed }^{*} \\
\text { mean }(S E) \\
(n=60)\end{array}$ & $\begin{array}{l}\text { Control }^{*} \\
\text { mean }(S E) \\
(n=60)\end{array}$ & $P$ value \\
\hline Open: & $\begin{array}{l}\mathbf{X}_{\mathrm{o}}(\mathrm{cm}) \\
\mathbf{Y}_{\mathrm{o}}(\mathrm{cm}) \\
\mathbf{X}_{\mathrm{s}}(\mathrm{cm}) \\
\mathbf{Y}_{\mathrm{s}}(\mathrm{cm}) \\
\mathbf{X}_{\mathrm{m}}(\mathrm{cm}) \\
\mathbf{Y}_{\mathrm{m}}(\mathrm{cm}) \\
\mathbf{R}_{\mathrm{m}}(\mathrm{cm}) \\
V e l(\mathrm{~cm} / \mathrm{s}) \\
\mathrm{L}(\mathrm{cm}) \\
A_{\mathrm{o}}\left(\mathrm{cm}^{2}\right) \\
\mathrm{A}_{\mathrm{e}}\left(\mathrm{cm}^{2}\right)\end{array}$ & $\begin{array}{r}0.49(0.41) \\
0.31(0.41) \\
0.32(0.11) \\
0.23(0.11) \\
0.28(0.11) \\
0.18(0.11) \\
0.35(0.09) \\
0.77(0.09) \\
15.40(0.09) \\
1.67(0.16) \\
0.84(0.19)\end{array}$ & $\begin{array}{r}0.54(0.42) \\
0.33(0.42) \\
0.34(0.11) \\
0.20(0.11) \\
0.28(0.11) \\
0.16(0.11) \\
0.35(0.10) \\
0.74(0.09) \\
14.70(0.09) \\
1.51(0.17) \\
0.76(0.19)\end{array}$ & $\begin{array}{l}\text { NS } \\
\text { NS } \\
\text { NS } \\
0 \cdot 0390 \\
\text { NS } \\
\text { NS } \\
\text { NS } \\
\text { NS } \\
\text { NS } \\
\text { NS } \\
\text { NS }\end{array}$ \\
\hline Closed: & $\begin{array}{l}\mathbf{X}_{\mathrm{o}}(\mathrm{cm}) \\
\mathbf{Y}_{\mathrm{o}}(\mathrm{cm}) \\
\mathrm{X}_{\mathrm{s}}(\mathrm{cm}) \\
\mathbf{Y}_{\mathrm{s}}(\mathrm{cm}) \\
\mathbf{X}_{\mathrm{m}}(\mathrm{cm}) \\
\mathbf{Y}_{\mathrm{m}}(\mathrm{cm}) \\
\mathrm{R}_{\mathrm{m}}(\mathrm{cm}) \\
\mathrm{Vel}(\mathrm{cm} / \mathrm{s}) \\
\mathbf{L}(\mathrm{cm}) \\
\mathrm{A}_{\mathrm{o}}\left(\mathrm{cm}^{2}\right) \\
\mathrm{A}_{\mathrm{e}}\left(\mathrm{cm}^{2}\right)\end{array}$ & $\begin{array}{r}0.83(0.32) \\
0.64(0.31) \\
0.40(0.10) \\
0.23(0.10) \\
0.32(0.10) \\
0.18(0.10) \\
0.40(0.09) \\
0.93(0.09) \\
18.50(0.09) \\
2.25(0.16) \\
1.03(0.17)\end{array}$ & $\begin{array}{r}0.89(0.33) \\
0.54(0.32) \\
0.34(0.11) \\
0.19(0.10) \\
0.27(0.10) \\
0.15(0.10) \\
0.34(0.09) \\
0.77(0.09) \\
15.40(0.09) \\
1.55(0.16) \\
0.74(0.17)\end{array}$ & $\begin{array}{l}\text { NS } \\
\text { NS } \\
0.01 \\
0.0034 \\
0.0167 \\
0.0035 \\
0.0028 \\
0.0014 \\
0.0014 \\
0.0002 \\
0.0018\end{array}$ \\
\hline
\end{tabular}

* Geometric mean value adjusted for height, weight, age, and drinking habits. $\mathrm{SE}=$ standard error on a log scale. meters obtained with the eyes open except for $Y_{s}$ (table 3). The controls' Romberg ratios (RRs) for Vel, $L, A_{o}$, and $A_{e}$ were near unity (table 4). There was at least a $20 \%$ difference between the values for closed and open eyes of the exposed Vel, $L, A_{0}$, and $A_{e}$ parameters.

Data of blood lead concentrations from the exposed subjects together with age, weight, and height were added as independent variables to the regression equations in which the parameters $X_{s}, Y_{s}, X_{m}, Y_{m}, R_{m}$, Vel, $L, A_{o}$, and $\mathrm{A}_{e}$ were dependent variables. The standardised estimates of blood lead for the $Y_{s}$, $Y_{m}, R_{m}, V e l, L, A_{o}$, and $A_{e}$ were in the range of -0.05 to $0 \cdot 1$. The present blood lead concentrations of the exposed group would seem not to have contributed significantly to the results found.

\section{Discussion}

Postural stability is controlled by sensory information from the vestibular, proprioceptive and visual systems with the cerebellum as the centre that controls the information. ${ }^{715}$ The main receptors involved are the vestibular organs, the exteroceptive and proprioceptive nerve endings, and the visual system. ${ }^{16}$

Posturography has been used to study the effect of exposure to industrial solvents on postural control..$^{7-9}$ Ledin et al concluded that static posturography may be useful in evaluation of lesions to the central nervous system induced by solvents. ${ }^{7}$

To record the posturography with open eyes, the worker stands upon a stable support. This corresponds to normal conditions of daily life. Under these conditions the sensory input available (of visual, vestibular, and

Table 4 Romberg ratios (RRs) for some postural sway parameters between exposed and control groups

\begin{tabular}{llll}
\hline $\begin{array}{l}\text { Postural sway } \\
\text { parameters }\end{array}$ & $\begin{array}{l}\text { Exposed } R R^{*} \\
(n=60)\end{array}$ & $\begin{array}{l}\text { Control } R R^{*} \\
(n=60)\end{array}$ & $P$ values \\
\hline Vel & 1.20 & 1.04 & 0.0206 \\
L & 1.20 & 1.04 & 0.0207 \\
$\mathrm{~A}_{\mathrm{o}}$ & 1.34 & 1.02 & 0.010 \\
$\mathrm{~A}_{\mathrm{e}}$ & 1.23 & 0.98 & 0.0311 \\
\hline
\end{tabular}

$\star$ Romberg ratio $(R R)=$ ratio of the postural sway parameters measured with eyes closed and eyes open. 
proprioceptive systems) can be used optimally. By closing the eyes the visual contribution is abolished. Bronstein reported that people with cerebellar disease and Parkinson's disease had significantly poorer postural stability when the eyes were closed than did normal subjects. ${ }^{15}$

It is known that compensatory mechanisms are put into action in cases of vestibular sensory insufficiency. ${ }^{1718}$ In cases of vestibular deficit these mechanisms simulate the action of the other non-involved sensory sources such as vision and proprioception. ${ }^{18}$ If under test conditions the other sensory inputs are not allowed to contribute-for example, tests with the visual input obliterated (tests with eyes closed)-postural instability may be elicited.

No significant differences were noted between the exposed and control groups for the sway parameters obtained with the eyes open except for $\mathrm{Y}_{\mathrm{S}}$ (table 3). Significant differences were found between the exposed and control groups for $X_{s}, Y_{s}, X_{m}, Y_{m}, R_{m}$, Vel, $L$, $A_{o}$, and $A_{e}$ when measured with the eyes closed. The findings indicate that the exposed workers needed the visual input for greater stability. This finding becomes clearer when the RRs were calculated for some of the postural sway parameters. The $R R$ is a powerful measure of effect of vision on postural stability. ${ }^{19}$ The controls' RRs for Vel, $L, A_{o}$, and $A_{e}$ were near unity suggesting that visual component for maintenance of postural stability is not significant (table 4) in this group of subjects. There is at least a $20 \%$ difference between the postural sway parameters of the exposed workers for $\mathrm{Vel}, \mathrm{L}, \mathrm{A}_{\mathrm{o}}$ and $\mathrm{A}_{e}$ with the eyes closed and eyes open.

It is unlikely that the workers exposed to lead had any vestibular disorders. None complained of any vestibular symptoms. Clinically, no abnormalities were detected.

Jeyaratnam et al in a study of 46 workers exposed to lead reported significantly prolonged somatosensory evoked potentials of the median (sensory) and posterior tibia, nerves among the exposed workers with a mean blood lead concentration of 48.7 $\mu \mathrm{g} / \mathrm{dl}^{20}$ The somatosensory evoked potential assesses the whole sensory neural axis inclusive of the proximal parts of the peripheral sensory nervous system (root and plexus). Lead may affect the muscle afferents, which results in the increased $R R$ among the exposed workers. Bhattacharya et al reported the results of a study of children with chronic exposures to lead. The mean blood lead concentration of the children was $23.4 \mu \mathrm{g} / \mathrm{dl}$, and the maximum blood lead concentration incurred during the second year of life was positively related to increases in postural sway. ${ }^{11}$

We were unable to establish a significant relation between blood lead concentrations and postural sway parameters-this is not unexpected. The blood lead concentrations of the exposed workers are a reflection of present not past exposure. It would be more appropriate to obtain the previous records of blood lead concentrations. We are in the process of trying to retrieve and collate the data.

In summary, this study showed that workers exposed to lead had significantly poorer postural stability than a control group. Lead may affect certain parts of the whole sensory neural axis resulting in postural instability when the visual input is cut off. Based on current blood lead concentrations, we were not able to obtain any significant correlation with the postural sway parameters.

This study was carried out with Research Grant RP920389 from the National University of Singapore.

1 Begbie GH. The effects of alcohol and varying amounts of visual information on a balancing test. Ergonomics 1966; 9:325-33.

2 Hufschmidt A, Dichgans J, Mauritz. Some methods and parameters of body sway quantification and their neuroparameters of body sway quantification and their neuro-
logical application. Archives of Psychiatry and Neurological logical application. Archives

3 Jones AW, Jennings D, Adolfson J, Hesser CM. Combined effects of ethanol and hyperbaric air on body sway and heart rate in man. Undersea Biomedical Research 1979; 6:15-25.

4 Lidegaard $O$, Jansen EL, Larsen TK. The influence of propanolol on postural stability. Acta Neurol Scand 1984;69:412-6.

5 Bhattacharya AP, Shukla R, Bornschein R, Dietrich K. Postural stability under low levels of alcohol. Ann Biomed Eng 1987;15:533-50.

6 Franks HM, Hagedorn J, Hensley VR, Hensley WJ, Starmer GA. The effect of caffeine on human performance, alone and in combination with ethanol. Psychopharmacologica 1975;45:177-81.

7 Ledin T, Odkvist LM, Moller C. Posturography findings in workers exposed to industrial solvents. Acta Otolaryngol (Stockh) 1989;107:357-61.

8 Antti-Poika $M$, Ojala $M$, Matikainen E, Vaheri E, Juntunen J. Occupational exposure to solvents and cerebellar, brainstem and vestibular functions. Int Arch Occup Environ Health 1989;6:397-401.

9 Moller C, Odkvist L, Larsby B, Tham R, Ledin T, Bergholtz L. Otoneurological findings in workers exposed to styrene. Scand $\mathcal{F}$ Work Environ Health 1990; 16:189-94.

10 Chia SE, Goh J, Lee G, Foo SC, Gan SL, Bose K, Jeyaratnam J. Use of a computerised postural sway measurement system for assessing workers exposed to manganese. Clin Exp Pharmacol Physiol 1993;20:549-53.

11 Bhattacharya A, Shukla R, Bornshein R. Postural disequilibrium quantification in children with chronic lead librium quantification in children with chronic lead
exposure: a pilot study. Neurotoxicology 1988;9:327-40.

exposure: a pilot study. Neurotoxicology 1988;9:327-40.
12 Bhattacharya A, Shukla R, Bornshein RL. Lead effects on postural balance of children. Environ Health Perspect
pottacharya A, Shukla R, Bornshein RL. Lead effects on 1990;89:35-42.

13 Linz DH, Barrett ET, Pflauumer JE, Keith RE. Neuropsychologic and postural sway improvement after $\mathrm{Ca}^{++}$-EDTA chelation for mild lead intoxication f Occup Med 1992;34:638-41.

14 Brodie KG, Routh MW. Trace analysis of lead in blood, aluminium and manganese in serum and chromium in urine by graphite furnace atomic absorption spectrometry. Clin Biochem 1984;17:19-26.

15 Bronstein AM, Hood JD, Gresty MA. Visual control of balance in cerebellar and parkinsonian syndromes. Brain 1990;113:769-79.

16 Hytonen M, Pyykko I, Aalto H, Starck J. Postural control and age. Acta Otolaryngol (Stockh) 1993;113:119-22.

17 Precht W, Dieringer N. Neuronal events paralleling functional recovery (compensation) following peripheral vestibular lesions. In: Berthoz A, Melvill-Jones G, eds. vestibular lesions. In: Berthoz A, Melvill-Jones $\mathrm{G}$, eds. Adaptive mechanisms in gaze control. Reviews in oculomo
research. Vol 1. Elsevier: Amsterdam, 1985, 251-86.

18 Flohr H, Bienhold H, Abeln W, Macskovics A. Concepts of vestibular compensation. In: Flor $\mathrm{H}$, Precht $\mathrm{W}$, eds. Lesion-induced neuronal plasticity in sensorimotor systems. Berlin: Springer-Verlag, 1981:153-72.

19 Ohashi N, Nakagawa H, Asai M. Contribution of vision to the stabilisation of body sway in patients with spinocerebellar degeneration. Acta Otolaryngol (Stockh) 1993 504(suppl): 117-9.

20 Jeyaramam J, Devathasan G, Ong CN, Phoon WO, Wong lead. Br f Ind Med 1985;42:173-7. 